\title{
Conditioned and Unconditioned Stimuli Increase Frontal Cortical and Hippocampal Acetylcholine Release: Effects of Novelty, Habituation, and Fear
}

\author{
Elio Acquas, Catriona Wilson, and Hans C. Fibiger \\ Division of Neurological Sciences, Department of Psychiatry, University of British Columbia, Vancouver, British Columbia, \\ Canada V6T $1 Z 3$
}

\begin{abstract}
Recent evidence showing that basal forebrain cholinergic neurons with projections to the frontal cortex and hippocampus are activated by behaviorally salient stimuli suggests that these neurons are involved in arousal and/or attentional processes. We sought in the present experiments to test this hypothesis by examining whether unconditioned stimuli (a tone and flashing light) that normally increase cortical and hippocampal acetylcholine (ACh) release would fail to do so after habituation (i.e., repeated presentation with no programmed consequences). In addition, the extent to which presentation of these stimuli would continue to increase ACh release when they had previously been paired with an aversive stimulus was investigated. Three experimental groups were used: habituation, novel stimuli, and conditioned fear. Subjects in each of these groups were placed in a training apparatus for twelve $200 \mathrm{~min}$ sessions. While the habituation group received extensive exposure to the tone and light during the training sessions, subjects in the novel stimuli group were placed in the apparatus but were never exposed to the tone or light during these sessions. The conditioned fear group was treated identically to the habituation group, with the addition that the tone and light were paired with footshock. On completion of these training schedules, all animals were implanted with microdialysis probes in the frontal cortex and hippocampus. Two days later, they were placed in the apparatus and the tone and light were presented to all
\end{abstract}

subjects during microdialysis. In the novel stimuli group, the tone and light (unconditioned stimuli) produced significant increases in frontal cortical and hippocampal ACh release. Similarly, in the conditioned fear group, presentation of the tone and light (conditioned stimuli) also significantly increased ACh release in frontal cortex and hippocampus. In contrast, in the habituation group the tone and light failed to significantly enhance ACh release in either structure. During the test session, the tone and light elicited a variety of arousal- and fear-related behaviors in the novel stimuli and conditioned fear groups. In contrast, subjects in the habituation group generally failed to respond to these stimuli.

These data indicate that cortically and hippocampally projecting basal forebrain cholinergic neurons are activated by conditioned and unconditioned stimuli that produce arousal in rats (novelty or conditioned fear). In contrast, presentation of these stimuli to habituated animals fails to enhance ACh release. These findings are consistent with a growing body of information indicating that ACh release in the cortex and hippocampus is reliably activated by behaviorally relevant stimuli. They also provide strong support for the hypothesis that cholinergic neurons in the basal forebrain are involved in arousal and/or attentional processes.

Key words: acetylcholine; basal forebrain; attention; arousal; microdialysis; cortex; hippocampus
The cholinergic innervation of the cerebral cortex and hippocampus originates largely from the cholinergic basal nuclear complex, a group of neurons in the basal forebrain delimited anteriorly by the medial septal nucleus and caudally by the nucleus basalis (Fibiger, 1982; Schwaber et al., 1987). Lesions of these basal forebrain neurons have been reported to result in impairments in memory (Bartus et al., 1985; Bartus et al., 1986; Olton and Wenk, 1987) and attention (Dunnett et al., 1991; Muir et al., 1992; Voytko et al., 1994). A potential clinical correlate of these findings has been provided by the discovery that Alzheimer's disease shows a characteristic loss of cholinergic neurons in the basal forebrain (Davies and Maloney, 1976; Perry et al., 1977, 1981; Davies, 1979; Whitehouse et al., 1982;

Received Dec. 7, 1995; revised Feb. 6, 1996; accepted Feb. 9, 1996.

This research was supported by the Medical Research Council of Canada. E.A. was supported by a postdoctoral long-term fellowship from the Human Frontiers Science Program Organization. The helpful comments of P. I. Mackenzie are gratefully acknowledged.

Correspondence should be addressed to Dr. Hans C. Fibiger, Division of Neurological Sciences, Department of Psychiatry, University of British Columbia, 2255 Wesbrook Mall, Vancouver, BC, Canada V6T $1 Z 3$.

Copyright $\odot 1996$ Society for Neuroscience $0270-6474 / 96 / 163089-08 \$ 05.00 / 0$
Sims et al., 1983), which parallels the deficits in cognition and attention associated with this condition (Sahakian et al., 1989, 1993; Eagger et al., 1991; Parasuraman and Martin, 1994).

Basal forebrain neurons can modulate the response of cortical neurons to conditioned stimuli and appear to be involved in cortical neuronal plasticity associated with conditioning (Pirch et al., 1991; Richardson and De Long, 1991). In the frontal cortex, changes in discharge activity produced by a conditioned stimulus are suppressed by lesions of the nucleus basalis (Rigdon and Pirch, 1986) or by local application of the muscarinic antagonist atropine (Rigdon and Pirch, 1986; Pirch et al., 1992). In contrast, iontophoretic application of $\mathrm{ACh}$ potentiates the activity of cortical neurons that respond to a conditioned stimulus (Pirch et al., 1992), and electrical stimulation of the basal forebrain facilitates cortical responses to auditory stimuli (Hars et al., 1993). In primates, the spontaneous activity of neurons in the basal forebrain is increased by stimuli associated with either rewarding (Richardson and De Long, 1990; Wilson and Rolls, 1990) or aversive events (Wilson and Rolls, 1990). These observations suggest that rather than being selectively responsive to the affective valence of a stimulus, these neurons respond to the arousing prop- 
erties of sensory stimuli (Richardson and De Long, 1988; Wilson and Rolls, 1990).

A number of studies have demonstrated a close relationship between cortical and hippocampal measures of arousal, the activity of neurons in the nucleus basalis and medial septal nucleus (Apostol and Creutzfeldt, 1974; Buzsaki et al., 1988; Metherate and Ashe, 1992; Sweeney et al., 1992), and increases in cortical (Casamenti el al., 1986; Rasmusson et al., 1992) or hippocampal ACh release (Dudar, 1975). It has also been demonstrated that increases in cortical and hippocampal ACh release are associated with behavioral arousal (Dudar et al., 1979; Nilsson et al., 1990; Day et al., 1991; Mizuno et al., 1991), anticipation and consumption of a palatable meal (Inglis et al., 1994), and presentation of sensory stimuli (Dudar et al., 1979; Inglis and Fibiger, 1995). On the basis of such studies, it has been suggested that increases in cortical and hippocampal ACh release play a role in arousal and/or attention (Inglis and Fibiger, 1995).

The present experiments were designed to explore further the circumstances under which sensory stimuli influence cortical and hippocampal $\mathrm{ACh}$ release, with a view toward elucidating their role in attentional processes. To this end, the activity of cholinergic neurons in the basal forebrain was monitored by recording changes in ACh release in rat frontal cortex and hippocampus during the presentation of conditioned or unconditioned stimuli. This was achieved by presenting the identical stimuli on a test session to three groups of animals with different histories: novel stimuli, habituation, and conditioned fear. Results from the novel stimuli group provided information about the response of these neurons to novel, unconditioned stimuli. Results from the habituation group provided information about the extent to which extensive previous exposure to the same stimuli would influence the subsequent responses of these cholinergic neurons to these stimuli. Finally, results from the conditioned fear group provided information about the responses of basal forebrain neurons to these stimuli when they had high behavioral salience as a consequence of previously being paired with an aversive event.

\section{MATERIALS AND METHODS}

Subjects. Male Long-Evans rats (Charles River, Québec, Canada) weighing $250-275 \mathrm{gm}$ at the beginning of the experiments were maintained in a colony room, in groups of two to three per cage, under a $12 \mathrm{hr}$ light/dark cycle (lights on at 7:30 A.M.) with food and water available ad libitum for at least $7 \mathrm{~d}$ before the beginning of experiments. Five days before training, the rats were housed in single cages and handled for $\sim 10$ min every morning.

Apparatus. Training was conducted in Plexiglas boxes $(27 \times 36 \times 42$ $\mathrm{cm}$ ), the walls of which were painted will black and white vertical stripes. Each box had a transparent Plexiglas cover with a mirror placed at an angle of $45^{\circ}$ to allow an indirect viewing of the rats. The floor of each box consisted of copper bars ( $3 \mathrm{~mm}$ diameter) that were fixed to the walls 5 $\mathrm{cm}$ above the bottom of the cage. In one box, the copper bars were connected to a shock generator and scrambler (Model E13-14, Coulborne Instruments, Allentown, PA). On the front panel of the boxes, two $15 \mathrm{~W}$ light bulbs and a sound generator were placed $5 \mathrm{~cm}$ below the lid. Each training chamber was located in a separate soundproof room, and training for each group was always conducted in the same box. The apparatus was automatically operated by a NOVA IV (Data General) microcomputer, equipped with M $\triangle \mathrm{NX}$ (GC Controls) software and interface, with local power supplies for each box. After each training session, each box was carefully wiped with paper towels soaked with a $10 \%(\mathrm{v} / \mathrm{v})$ solution of bleach in tap water, rinsed with water, and dried.

Training procedure and schedule. Training occurred over a period of 8 $\mathrm{d}$ and had two main objectives. First, it was necessary for the conditioned fear group to learn the CS (tone/light)-UCS (shock) association. To this end, on some sessions the CS was intermittently paired with UCS. Second, it was important that contextual fear conditioning be minimized and that fear conditioning to discrete cues be maximized, so that the former would not influence the ACh dialysis measurements. To this end,
Table 1. Summary of behavioral procedures

\begin{tabular}{lllll} 
& & Novel stimuli & Habituation & Conditioned fear \\
\hline Day 1 & A.M. & BOX (N) & BOX (N) & BOX (N) \\
Day 2 & A.M. & BOX (N) & BOX (T \& L) & BOX (T, L \& S) \\
& P.M. & BOX (N) & BOX (T \& L) & BOX (N) \\
Day 3 & A.M. & BOX (N) & BOX (T \& L) & BOX (N) \\
& P.M. & BOX (N) & BOX (N) & BOX (T, L \& S) \\
Day 4 & A.M. & BOX (N) & BOX (T \& L) & BOX (N) \\
& P.M. & BOX (N) & BOX (N) & BOX (N) \\
Day 5 & A.M. & BOX (N) & BOX (N) & BOX (N) \\
& P.M. & BOX (N) & BOX (T \& L) & BOX (T, L \& S) \\
Day 6 & A.M. & BOX (N) & BOX (N) & BOX (T, L \& S) \\
& P.M. & BOX (N) & BOX (N) & BOX (T, L \& S) \\
Day 7 & A.M. & Surgery & Surgery & Surgery \\
Day 8 & A.M. & BOX (N) & BOX (T \& L) & BOX (N) \\
& P.M. & BOX (N) & BOX (N) & BOX (T, L \& S) \\
Day 9 & A.M. & Microdialysis & Microdialysis & Microdialysis
\end{tabular}

On days 2-6 and day 8, the order of presentation of $\mathrm{S}^{-}(\mathrm{N}$, Habituation group and Conditioned fear) and of $\mathrm{S}^{+}$sessions ( $\mathrm{T} \& \mathrm{~L}$, Habituation group; T, L \& $\mathrm{S}$, Conditioned fear group) was randomized for each rat. $(\mathrm{N})$, No tone or light stimuli; ( $T$ \& L), torte and light; ( $T, L$ \& S), tone, light and shock.

${ }^{a}(T, L \& S)$, Shock sessions were: 1st FR1, 2nd FR2, 3rd and 4th VR3.

${ }^{b}(\mathrm{~T}, \mathrm{~L} \& \mathrm{~S})$, Shock sessions were: one FR1 and three VR3, in random order.

training sessions were divided into some in which there was no presentation of the CS or UCS $\left(\mathrm{S}^{-}\right)$and some in which these stimuli were presented together $\left(\mathrm{S}^{+}\right)$. This procedure permitted the discrete conditioned stimuli to be presented late and unexpectedly on the dialysis test session, a session that began without such stimuli and therefore would be considered by the animal to be an $\mathrm{S}^{-}$session. In addition, by presenting the CSs late in the test session, the effects of handling on $\mathrm{ACh}$ release would have subsided, thus permitting the establishment of a new baseline from which to measure the effects of the tone and light stimuli in the absence of possible confounds produced by handling of contextual fear.

On day 1, each animal was placed in the appropriate training box for $1 \mathrm{hr}$, but no stimuli were presented. On the subsequent $6 \mathrm{~d}$ (days 2-6 and day 8), each rat was placed in a box for $200 \mathrm{~min}$, twice a day for a total of 12 training sessions. Training started every day between 8:30 and 9:30 A.M., with the second daily session starting 1 hr after the end of the first (indicated by P.M. in Table 1). Rats were housed in the colony room for the hour between training sessions. Subjects in the novel stimuli group were not exposed to the auditory and visual stimuli during any of the 12 training sessions ( $N=$ No Events, see Table 1). For subjects in the habituation and conditioned fear groups, the 12 sessions were divided into six $\mathrm{S}^{-}$and $\operatorname{six} \mathrm{S}^{+}$sessions, occurring in a random order for each subject (see Table 1 for example). No discrete stimuli were presented to the subjects in the habituation and conditioned fear groups during the $\mathrm{S}^{-}$sessions (N, Table 1). However, during the $\mathrm{S}^{+}$ sessions the auditory (tone) and visual (light) stimuli (T \& L, Table 1) were presented to the subjects in the habituation group, and the same stimuli intermittently paired with footshock $(T, L \& S$, Table 1$)$ were presented to subjects in the conditioned fear group. Each $\mathrm{S}^{+}$session consisted of four 30 min and four 20 min periods, which alternated throughout the $200 \mathrm{~min}$ session. The auditory stimulus (continuous tone, $80 \mathrm{~dB}$ ) and the visual stimulus (two $15 \mathrm{~W}$ flashing lights, $500 \mathrm{msec}$ on $/ 500 \mathrm{msec}$ off) were presented for $20 \mathrm{sec}$ every $2 \mathrm{~min}$ during each of the four $30 \mathrm{~min}$ periods (i.e., a total of 15 times per 30 min period). During the four 20 min periods, the animals remained in the boxes but no stimuli were presented. Footshock $(0.5 \mathrm{~mA}, 1$ $\mathrm{sec}$ on $/ 1 \mathrm{sec}$ off over $20 \mathrm{sec}$ ) was delivered to rats in the conditioned fear group with each $20 \mathrm{sec}$ presentation of the visual and auditory stimuli (fixed ratio $1, F R 1$ ) during the first $30 \mathrm{~min}$ period of the first $200 \mathrm{~min}$ session. The shock began at the onset of the auditory and visual stimuli and ended with their termination. During the second $30 \mathrm{~min}$ period of the first $200 \mathrm{~min}$ session, footshock was delivered on an FR2 schedule. In the remaining two 30 min periods of the first 200 min session, footshock was delivered according to a variable ratio schedule whereby footshock was paried, on average, with every third presentation of the tone and light (i.e., a variable ratio 3 schedule, VR3). In all subsequent $\mathrm{S}^{+}$sessions, footshock was delivered using the FR1 schedule randomly in one of the four 30 min periods, while the remaining three 30 min periods used the VR3 schedule. 


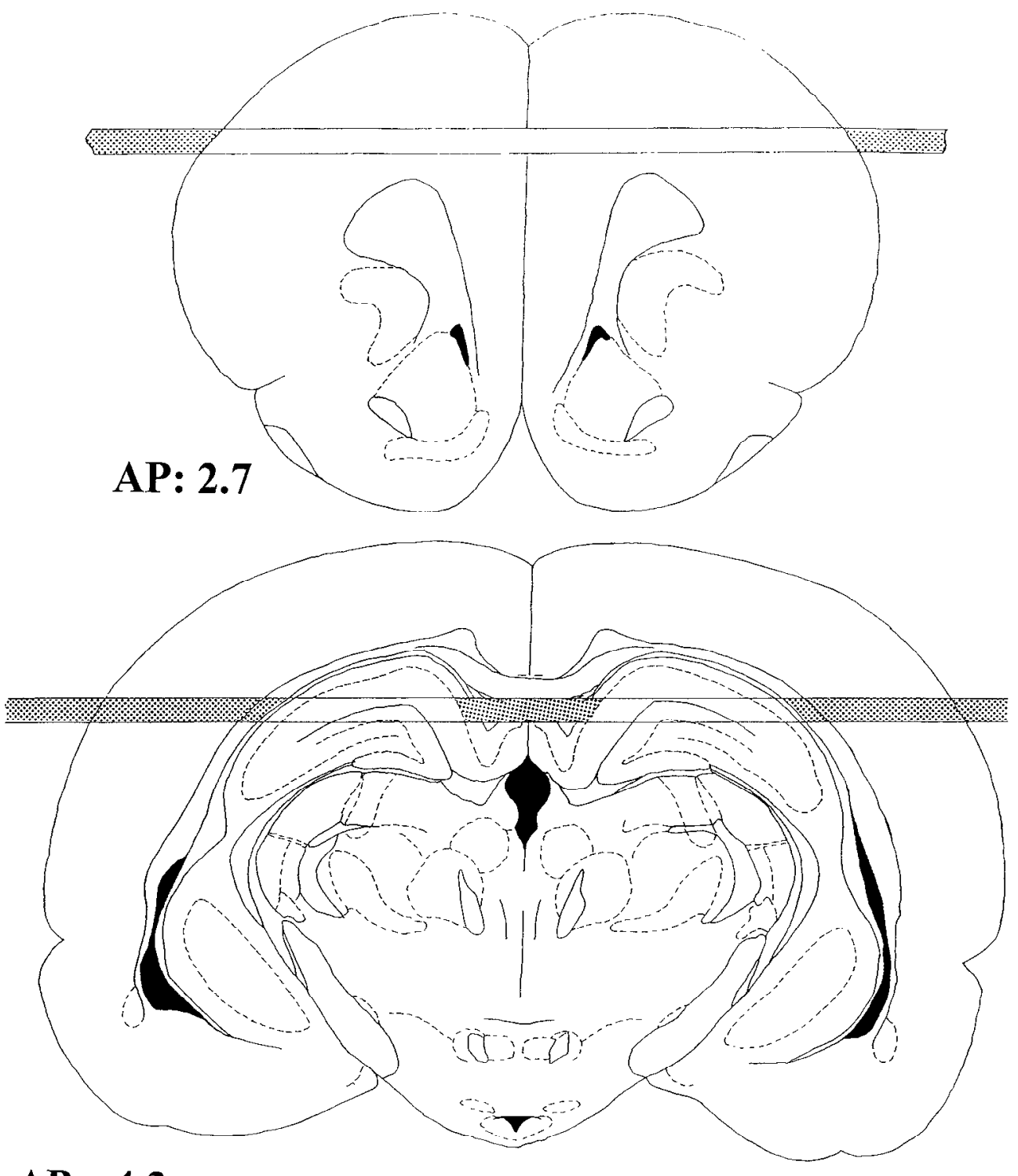

Figure 1. Schematic representation of the location of the microdialysis probes redrawn from Paxinos and Watson (1986). Shaded areas of the membranes represent the parts covered with epoxy glue. AP, 2.7: frontal cortex (top). AP, -4.3: hippocampus (bottom).
Surgery. On day 7 of training, rats were anesthetized with sodium pentobarbital $(60 \mathrm{mg} / \mathrm{kg}$, i.p.) and stereotaxically implanted with two horizontal microdialysis probes (Imperato and Di Chiara, 1985), one through the frontal cortex and the other through the dorsal hippocampus (Inglis et al., 1994; Inglis and Fibiger, 1995). The coordinates, measured from bregma, were AP $=+2.7 \mathrm{~mm}, \mathrm{DV}=-2.5 \mathrm{~mm}$ for the frontal cortex and $\mathrm{AP}=-4.3 \mathrm{~mm}, \mathrm{DV}=-3.3 \mathrm{~mm}$ for the hippocampus according to the atlas of Paxinos and Watson (1986). Dialysis membranes, consisting of a polyacrylonitrile/sodium methallyl sulfonate copolymer (AN 69 Filtral 8, Hospal Industrie, France), were covered with epoxy glue along their length except for 10.9 and $6.8 \mathrm{~mm}$ corresponding to the active surfaces of the cortical and the hippocampal prohes, respectively (Fig. 1). Immediately after surgery, the rats were housed in Plexiglas cages $(35 \times$ $35 \times 25 \mathrm{~cm}$ ) (dialysis cages), where they received food and water ad libitum.

Microdialysis experiments. On the second postsurgical day, behavioral testing with concurrent on-line microdialysis sampling was conducted. Inlet cannulae were attached to an infusion pump (Harvard Apparatus) via polyethylene tubing (PE-10, Becton Dickinson, Rutherford, NJ; $50 \mu \mathrm{l}$ volume), and outlet cannulae were similarly connected to the sample loops of 10-port HPLC valves (Valco Instruments, model C10W). Each valve was electrically operated by a digital valve sequence programmer (Valco Instruments) automatically injecting the sample for HPLC-ECD analysis every $10 \mathrm{~min}$. The perfusion solution contained $125 \mathrm{~mm} \mathrm{NaCl}, 3$ $\mathrm{mM} \mathrm{KCl}, 1.2 \mathrm{mM} \mathrm{CaCl}_{2}, 1 \mathrm{~mm} \mathrm{MgCl}$, and $23 \mathrm{~mm} \mathrm{NaHCO}$ in aqueous potassium phosphate buffer ( $1 \mathrm{mM}, \mathrm{pH} 7.4)$. To achieve reliably detectable amounts of $\mathrm{ACh}$ in the dialysate, the reversible acetylcholinesterase inhibitor neostigmine bromide $0.1 \mu \mathrm{M}$ (Sigma, St. Louis, MO) was added to the perfusion solution. ACh was assayed by HPLC-ECD in conjunction with an enzyme reactor (Damsma et al., 1987). ACh and choline were separated using a reverse-phase Chromspher $\mathrm{C}_{18} 5 \mu \mathrm{m}$ (Merck, Darmstadt, Germany) column $(75 \times 2.1 \mathrm{~mm})$. The mobile phase passed directly through the enzyme reactor $(10 \times 2.1 \mathrm{~mm})$ containing acetylcholinesterase (EC 3.1.1.7; Sigma, type VI-S) and choline oxidase (EC 1.1.3.17; Sigma). ACh and choline were quantitatively converted into hydrogen peroxide, which was electrochemically detected at a platinum working electrode set at $500 \mathrm{mV}$ versus an $\mathrm{Ag} / \mathrm{AgCl}$ reference electrode (BAS LC-4B). The mobile phase was an aqueous potassium phosphate buffer (1.9 mM $\mathrm{K}_{2} \mathrm{HPO}_{4}, 0.2 \mathrm{~mm}$ tetramethyl ammonium hydroxide, $\mathrm{pH} 8$ ) delivered at a constant flow of $0.4 \mathrm{ml} / \mathrm{min}$ by an HPLC pump (LKB 2150). The chromatograms were recorded on 2-pen chart recorders (Kipp \& Zonen, BD-41). The detection limit of the assay was $\sim 50 \mathrm{fmol} / \mathrm{sample}$. ACh standards $(20 \mu \mathrm{l}, 0.1 \mu \mathrm{M})$ were injected every 60 to $90 \mathrm{~min}$ to monitor detector sensitivity, and sample concentrations were corrected accordingly. Between 8:30 and 9:30 A.M. on day 9, the rats remained in their dialysis cages and were moved from the colony room to a soundproof room similar to the room in which the training had previously taken place. Each rat was connected to the microdialysis equipment. After stable baselines were obtained ( $90-180 \mathrm{~min}$ from the beginning of sample collection), each animal was moved from the dialysis cage into the test 
Table 2. Tone/light-induced increases in ACh release (fmol/sample)

\begin{tabular}{llc} 
& Cortex & Hippocampus \\
\hline Novel stimuli & $436 \pm 99^{*}$ & $169 \pm 59^{*}$ \\
Habituation & $153 \pm 114$ & $85 \pm 78$ \\
Conditioned fear & $556 \pm 185^{*}$ & $212 \pm 62^{*}$
\end{tabular}

Differences in ACh release (in fmol/sample) between the average of three prestimulus baseline values and the second (i.e., peak) sample obtained during the tone/light presentation.

*Tone/light stimulation value significantly different from baseline values, $p<0.02$ (paired two-tailed Student's $t$ test).

box (which was identical to the training boxes), without interrupting sample collection. Two hours after being placed in the test box, the auditory and visual stimuli were presented to subjects from all groups. These stimuli were delivered for $20 \mathrm{sec}$ every $2 \mathrm{~min}$ for a total of 15 presentations over $30 \mathrm{~min}$. Footshock was never delivered during the test session. At the conclusion of the experiments, the rats were killed and the brains were removed and processed for histological examination of the probe positions. Data from animals in which the membranes were located outside the frontal cortex and the hippocampus were discarded.

Behavioral analyses. During the test session on day 9, the behavior of each rat was observed or videotaped during the presentation of the auditory and visual stimuli. Each behavior was assigned to one of three categories: inactive, locomotion/rearing, and fear-related behaviors. The inactive category included those behaviors in which the rats showed no motor responses to the tone and the light and remained resting on the floor of the cage. The locomotion/rearing category included sniffing, rearing, locomotion and grooming. Fear-related behaviors included prolonged alert immobility (freezing) or head movements in the alert position that were not accompanied by body movements. Also included in the latter category were jumping, flinching, walking along the walls of the cage, wet dog shakes, and body stretching during locomotion.

Rasal acetylcholine output, data analysis, and statistics. Basal ACh (fmol/ sample \pm SEM) levels were calculated as the average of six pretreatment samples for each experimental group in the dialysis chamber, i.e., before being introduced into the experimental chamber (Box). The overall baseline concentrations of $\mathrm{ACh}$ in the dialysates were $446 \pm 90(n=19)$ and $258 \pm 19(n=20)$ in the frontal cortex and hippocampus, respectively. Two different baselines were calculated in these experiments: the first was in the dialysis cage (before moving the rats into the experimental chamber), and the second was in the experimental chamber before the presentation of the auditory and visual stimuli. Each baseline included the last six pretreatment samples. The baseline sample immediately before moving rats into the test chamber (Box) or before the presentation of discrete sensory stimuli (Tone \& Light) was not included in the average for the calculation of the baseline and was used in the statistical analyses. Data were expressed as the percent of each rat's baseline value. ANOVAs, with time as the repeated measure, were used to analyze the effects of moving the rats into the box, and the effects of the auditory and visual stimuli and the nontransformed dialysis data arc shown in Table 2. Huynh-Feldt corrections for repeated measures were used. Reported values refer to the main effect of the experimental treatment. Dunnett's post hoc analyses were applied for multiple comparisons. Statistical significance for each analysis was set at $p<0.05$.

\section{RESULTS}

\section{Behavioral responses}

Figure 2 shows the behavioral responses of rats in the novel stimuli, habituation, and conditioned fear groups on the test day. Subjects in the novel stimuli group (Fig. 2, lop panel) mainly displayed fear-related behaviors that tended to increase over the 30 min test session. Rats in the habituation group (Fig. 2, middle panel) were mainly inactive during the test session, and this tended to increase over the course of the session so that by the last $10 \mathrm{~min}$ the great majority (94\%) of animals displayed behaviors in this category. Rats in the conditioned fear group (Fig. 2, bottom panel) mainly displayed fear-related behaviors throughout the 30 min test session.
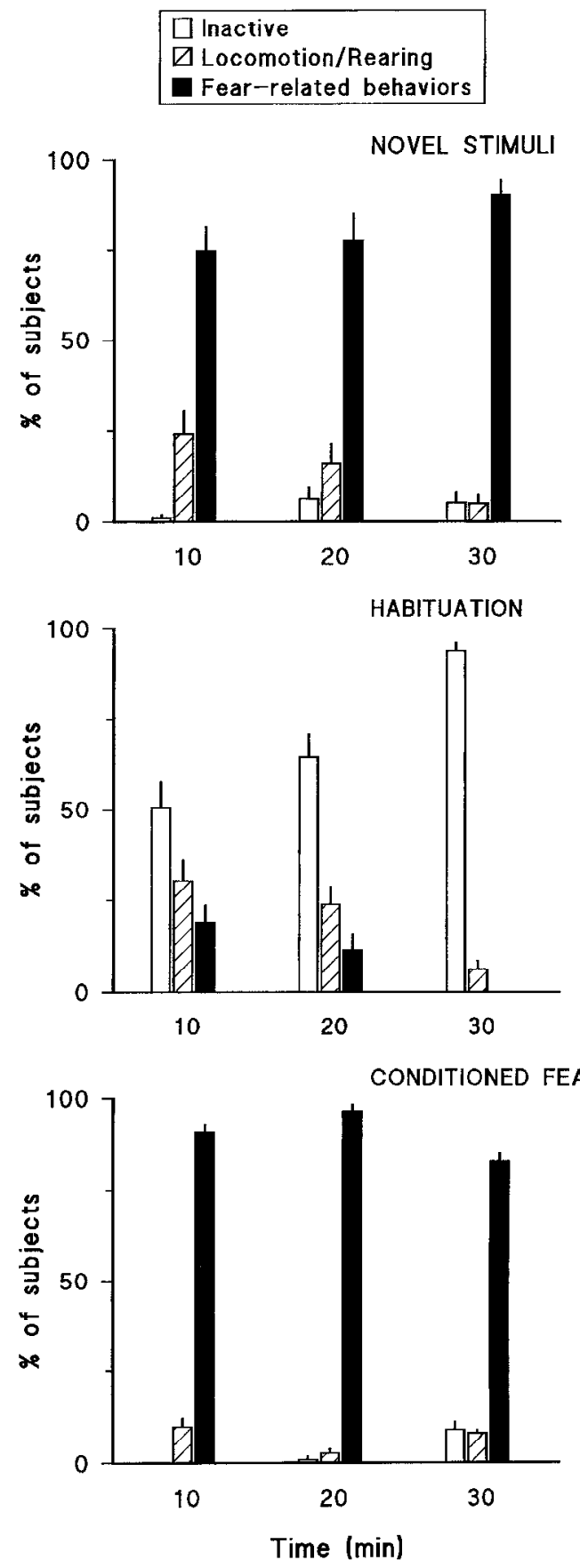

Figure 2. Behavioral responses of rats in the novel stimuli, habituation, and conditioned fear groups on the test session. Data are expressed as the percent of subjects in each group that displayed behaviors included in one of the three categories over three consecutive $10 \mathrm{~min}$ periods (see Materials and Methods for a detailed description of behaviors included in these categories).

\section{$\mathrm{ACh}$ release}

Microdialysis results from frontal cortex and hippocampus are presented in Figures 3 and 4, respectively. Moving the rats from the dialysis cage into the test chamber (Box, Fig. 3) produced sharp increases in cortical $\mathrm{ACh}$ release in all groups. These increases were statistically significant in all three groups: novel stimuli $\left[F_{(4.4,22.35)}=7.03, p<0.0001\right]$, habituation $\left[F_{(5,20)}=6.22\right.$, $p<0.001]$, and conditioned fear $\left[F_{(2.05,12.3)}=12.03, p<0.0001\right]$. ANOVAs on the first three samples of cortical dialysates in the 

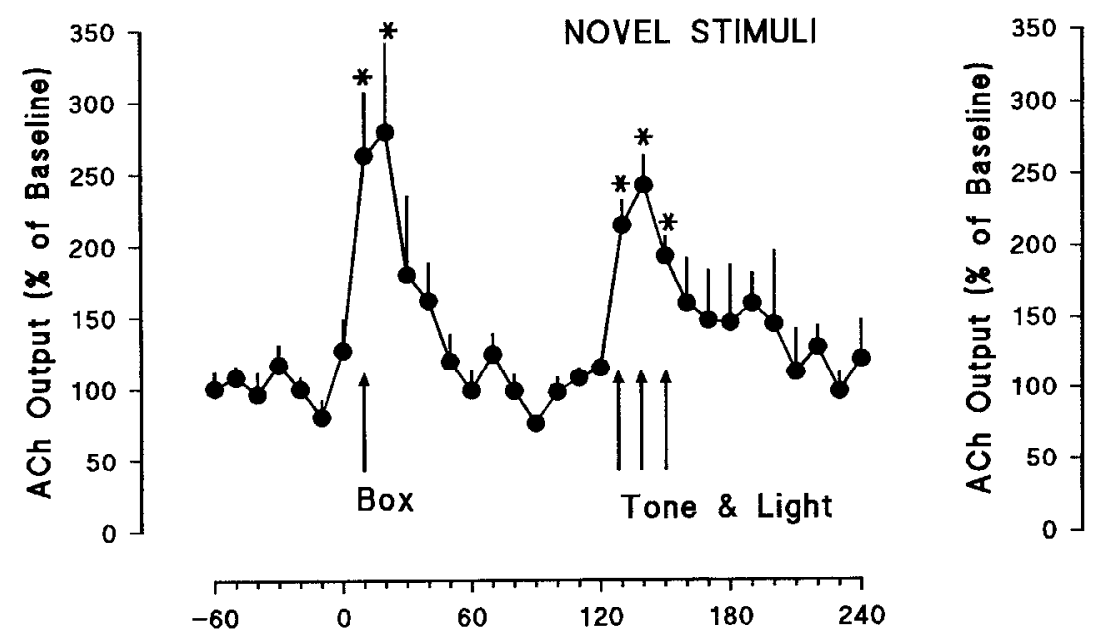

NOVEL STIMULI
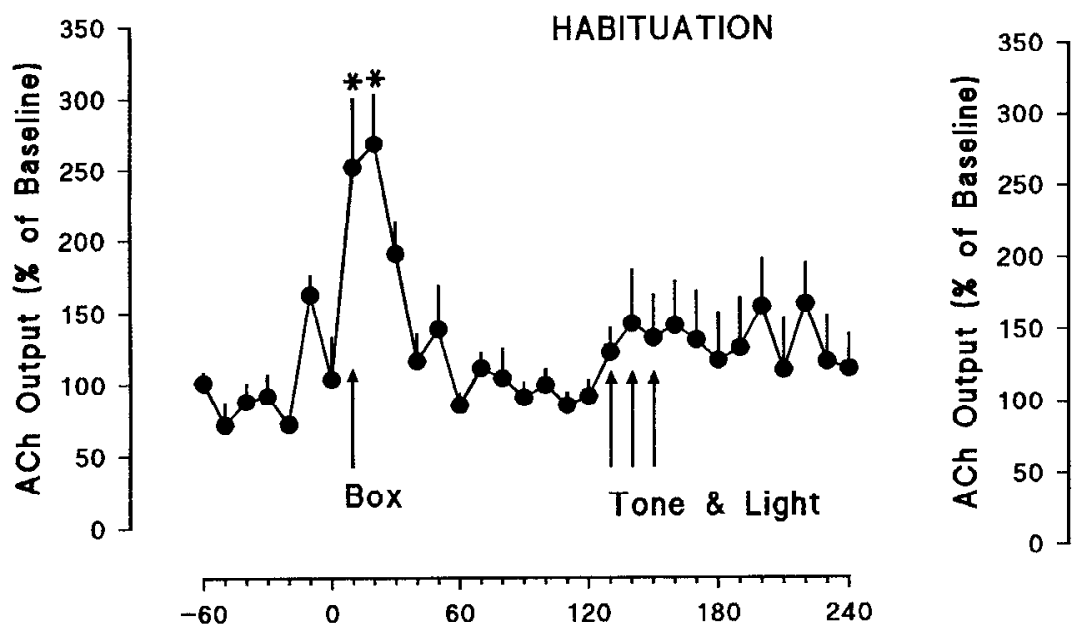

HABITUATION
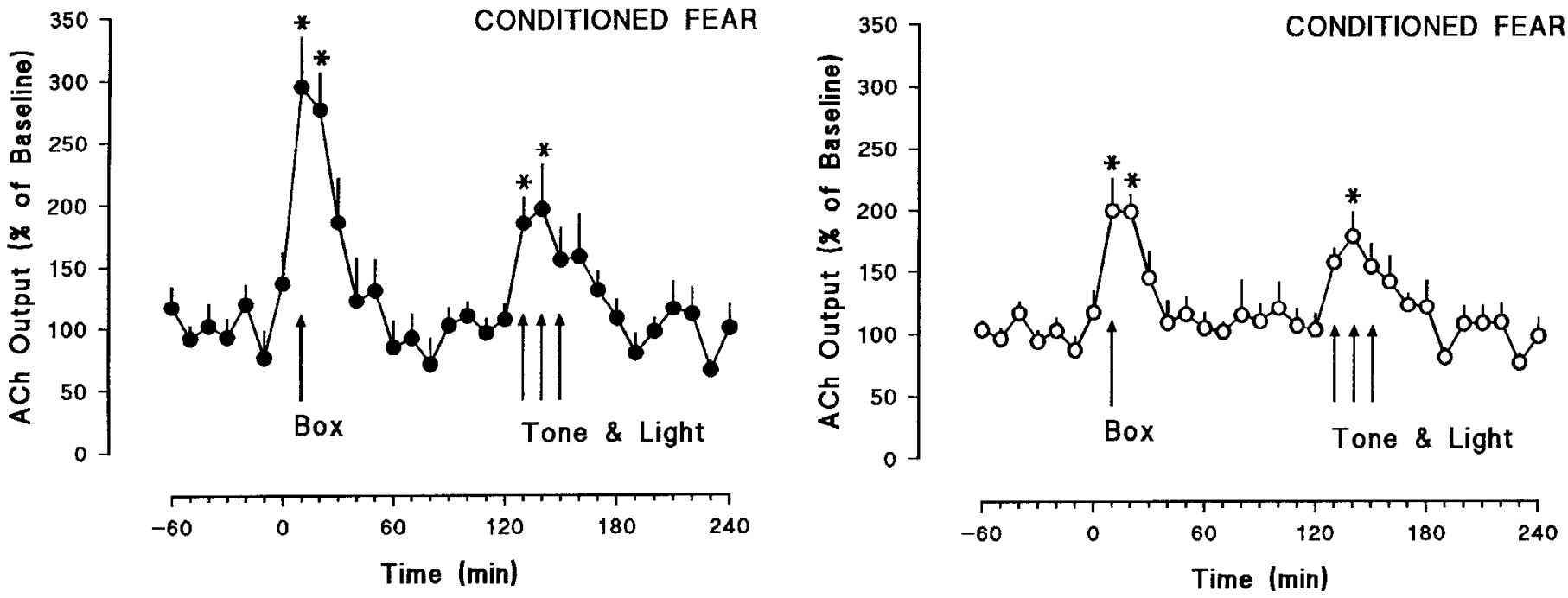

Figure 3. Frontal cortical dialysate concentrations of ACh expressed as the percent change from the average of the last six baseline values + SEM. The Box arrows indicate the time at which the rats were moved from the dialysis cage (baseline) into the test chamber. The Tone \& Light arrows indicate the $30 \mathrm{~min}$ period during which the auditory and visual stimuli were presented. The top panel shows results from the novel stimuli group $(n=6)$, and the middle and bottom panels show the habituation $(n=6)$ and conditioned fear groups $(n=7)$, respectively. Asterisks indicate significant difference from baseline, $p<0.05$.

Figure 4. Hippocampal dialysate concentrations of ACh expressed as the percent change from the average of the last six baseline values + SEM. The Box arrows indicate the time at which the rats were moved from the dialysis cage (baseline) into the test chamber. The Tone \& Light arrows indicate the $30 \mathrm{~min}$ period during which the auditory and visual stimuli were presented. The top panel shows results from the novel stimuli group $(n=6)$, and the middle and bottom panels show the habituation $(n=6)$ and conditioned fear groups $(n=8)$, respectively. Asterisks indicate significant difference from baseline, $p<0.05$. 
box indicated that there were no significant differences in the effects of handling among the three groups $\left[F_{(2,15)}=0.04\right.$, not significant $]$. Two hours after the animals were placed into the test chamber (Box, Fig. 3), auditory and visual stimuli, identical to those used in the training sessions, were presented for $30 \mathrm{~min}$. Presentation of the tone and light combination produced significant increases in cortical $\mathrm{ACh}$ release in the novel stimuli $\left[F_{(2.58,12.9)}=11.53, p<0.0001\right]$ and conditioned fear $\left[F_{(3,18)}=4.65, p<0.01\right]$ groups, but failed to produce significant effects in the habituation group $\left[F_{(1.53,7.65)}=\right.$ 1.55, not significant] (see also Table 2).

A similar pattern of results was obtained with respect to hippocampal ACh release (Fig. 4). Moving the rats into the test box significantly increased hippocampal $\mathrm{ACh}$ release in the novel stimuli $\left[F_{(4.9,24.5)}=9.32, p<0.0001\right]$, habituation $\left[F_{(4.7,23.5)}=\right.$ $5.49, p<0.002]$, and conditioned fear $\left[F_{(4.45,31.15)}=12.26, p<\right.$ $0.0001]$ groups. ANOVAs of the first three samples of hippocampal dialysates in the box indicated that there were no significant differences among the groups in the increases produced by the handling procedure $\left[F_{(2,17)}=0.43\right.$, not significant $]$. Presentation of the auditory and visual stimuli produced significant increases of hippocampal $\mathrm{ACh}$ release in both the novel stimuli and the conditioned fear groups $\left[F_{(2.85,14.25)}-5.92, p<0.007\right.$ and $\left.F_{(1.8,12.6)}=4.47, p<0.01\right]$, respectively. In contrast, presentation of the tone and the light failed to enhance hippocampal $\mathrm{ACh}$ release $\left[F_{(1.68,8.4)}=1.64\right.$, not significant $]$ in the habituation group (see also Table 2).

Statistical analyses were also conducted on nontransformed dialysis data from the three groups of animals. In these analyses (repeated-measures ANOVA), the last three prestimulation (tone/light) values (in fmol/sample) were compared with the values obtained during the peak increase seen during the tone/light stimulation period, that is, during the second dialysate sample in the stimulation period (see Figs. 3, 4). In accordance with the conclusions based on the transformed (\% baseline) data, the tone and light produced significant absolute increases in $\mathrm{ACh}$ release in the novel stimuli [cortex: $F_{(1.53,7.65)}=16.81, p<0.002$; hippocampus: $\left.F_{(1.83,9.15)}=6.77, p<0.01\right]$ and conditioned fear groups [cortex: $F_{(1.62,9.92)}-6.69, p<0.003$; hippocampus: $\left.F_{(2.43,17.01)}=8.92, p<0.001\right]$. In contrast, these increases were not statistically significant in the habituation group [cortex: $F_{(1.42,10.65)}=1.60$ (not significant); hippocampus: $F_{(1.98,9.90)}=$ 1.19 (not significant)]. Table 2 shows the difference scores (peak stimulation value minus baseline value) for the two brain structures in each of the three groups.

\section{DISCUSSION}

The results of these experiments confirm and extend previous observations indicating that unconditioned sensory stimuli significantly increase frontal cortical and hippocampal ACh release (Inglis and Fibiger, 1995). The present findings also demonstrate (1) that conditioned stimuli can increase cortical and hippocampal $\mathrm{ACh}$ release, and (2) that the increases in ACh release produced by unconditioned stimuli are significantly reduced by habituation.

In the present study, frontal cortical and hippocampal $\mathrm{ACh}$ release was monitored simultaneously in the same subjects. This differs from a previous report from this laboratory in which the effects of sensory stimuli were studied in these two brain regions in different groups of animals (Inglis and Fibiger, 1995). The current procedure had the advantage of permitting direct comparisons between the cholinergic activity in frontal cortex and hippocampus of the same animal. The results show that changes in $\mathrm{ACh}$ release in frontal cortex and hippocampus followed nearly identical patterns in each of the experimental groups. Although there may be rare instances in which frontal cortical and hippocampal ACh release is differentially regulated (Inglis et al., 1994; Inglis and Fibiger, 1995), the present findings are consistent with a growing body of evidence indicating that neurons in the cholinergic basal nuclear complex generally function as a single nuclear group (Schwaber et al., 1987).

The principal finding of this study is that auditory and visual stimuli produced different changes in frontal cortical and hippocampal $\mathrm{ACh}$ release depending on the circumstances under which they were presented. Thus, when these stimuli were novel, they elicited significant increases in ACh release. This result is in agreement with previous findings showing that stimuli from a variety of sensory modalities (auditory, tactile, olfactory, or visual) increase $\mathrm{ACh}$ release in rat frontal cortex (Inglis and Fibiger, 1995) and hippocampus (Dudar et al., 1979; Nilsson et al., 1990; Inglis and Fibiger, 1995). In contrast, subjects in the habituation group that had previously received extensive exposure to these stimuli in the absence of programmed consequences failed to show significant increases in $\mathrm{ACh}$ release when these stimuli were presented during the test session. The fact that these animals showed little behavioral response to these stimuli during the test session (Fig. 2) indicates that the extensive exposure during the training sessions had resulted in considerable habituation. In contrast, when the same stimuli were presented to animals in which these stimuli had previously been associated with footshock, they produced robust increases in cortical and hippocampal ACh release (conditioned fear group).

A number of studies have demonstrated that cortical (Day et al., 1991) and hippocampal (Dudar et al., 1979; Day et al., 1991; Mizuno et al., 1991) $\Lambda \mathrm{Ch}$ release is positively related to behavioral arousal as defined by locomotor activity. In the present study, a large majority of rats $(>90 \%)$ in the novel stimuli and conditioned fear groups displayed fear-related behaviors during the presentation of the sensory stimuli. Because fear-related behaviors consisted of freezing or alert immobility, the observation that in these two groups these stimuli produced significant increases in cortical and hippocampal $\mathrm{ACh}$ release provides direct evidence for a dissociation between locomotor activity and increases of $\mathrm{ACh}$ release in these two brain regions. It is noteworthy that a similar dissociation has been noted in an electrophysiological study by Richardson and De Long (1990) in which the activity of primate nucleus basalis neurons was recorded during the performance of a go/no-go task. Specifically, these neurons showed changes in activity when monkeys performed correctly regardless of whether the task called for motor activity or immobility. Together with the present results, these observations are consistent with the view that increased cortical and hippocampal $\mathrm{ACh}$ release occurs when animals become aroused by and/or attend to behaviorally salient stimuli (Inglis et al., 1994; Inglis and Fibiger, 1995).

The procedure of handling the rats when moving them from the dialysis cage into the test box produced significant increases of cortical and hippocampal ACh release in all groups. Similar handling effects on cortical and hippocanipal ACh release have been reported previously (Nilsson et al., 1990; Day and Fibiger, 1992, 1994). However, considering that the subjects had been handled extensively before the test session, this finding was somewhat unanticipated. For subjects in the conditioned fear group, the contextual stimuli in the test chamber (box) may have been conditioned to fear as well. In view of the evidence for an important role of the hippocampus in contextual fear conditioning (Selden et al., 1991; Kim and Fanselow, 1992; Phillips and Le 
Doux, 1994), the increases of hippocampal ACh release may have been related to contextual conditioning in the conditioned fear group. However, this interpretation is not supported by the finding that identical increases were observed in the novel stimuli and the habituation groups. It appears, therefore, that these increases of ACh release are best interpreted as being attributable to the arousing effects of handling and of being moved from one environment to another.

Low-voltage fast activity in the cortex and theta activity in the hippocampus can be produced by electrical stimulation of the nucleus basalis (Casamenti et al., 1986; Metherate and Ashe, 1992; Rasmusson et al., 1992) and medial septal nucleus (Krnjevic and Ropert, 1982) respectively, and both correlate positively with enhanced ACh release in these structures (Dudar, 1975; Casamenti et al., 1986; Rasmusson et al., 1992) and with measures of behavioral arousal (Apostol and Creutzfeldt, 1974; Buzsaki et al., 1988; Sweeney et al., 1992). In monkeys, changes in the discharge activity of neurons in the basal forebrain are produced by stimuli that are either associated with rewards (Rolls et al., 1979; Richardson and De Long, 1988, 1990; Wilson and Rolls, 1990) or with aversive events (Wilson and Rolls, 1990; Richardson and De Long, 1991). Pharmacological and physiological studies point to a critical role for $\mathrm{ACh}$ in the facilitation of cortical neuronal responses to sensory stimuli, as demonstrated in visual (Sillito and Kemp, 1983), auditory (Metherate et al., 1990; Metherate and Ashe, 1992), and sensorimotor (Metherate et al., 1987) cortices. In this regard, the increases in cortical and hippocampal ACh release obtained in the present study are consistent with a role for $\mathrm{ACh}$ in the modulation of cortical and hippocampal functions related to behaviorally relevant stimuli. Thus, by increasing the signal-to-noise ratio of such stimuli, enhanced $\mathrm{ACh}$ release in these structures may be a neurochemical substrate for vigilance or selective attention.

Several lines of research suggest that basal forebrain cholinergic neurons subserve attentional functions. This evidence derives partly from lesion studies in which attentional focusing deficits have been correlated with decreases in the activities of cholinergic markers such as choline acetyltransferase and acetylcholinesterase (Muir et al., 1992, 1993, 1994; Voytko et al., 1994). These deficits can be ameliorated by pharmacological interventions that enhance cholinergic transmission (Muir et al., 1993, 1994) and by intracortical grafts containing embryonic basal forebrain cholinergic cells (Muir et al., 1992). In addition, the muscarinic receptor antagonist scopolamine disrupts performance on a selective attention task in rats (Jones and Higgins, 1995) and produces deficits in a sustained attention task in monkeys (Callahan et al., 1993). Some of the tasks used to assess attention in animals are similar to those used to assess attentional deficits in humans (Broks et al., 1988; Sahakian et al., 1993), and a growing body of evidence points to impaired cholinergic mechanisms as a substrate for the attentional deficits found in senile dementia and Alzheimer's disease (Sahakian et al., 1989, 1993; Eagger et al., 1991; Parasuraman and Martin, 1994; Sarter, 1994). It is noteworthy in this regard that we have recently found that $d$-amphetamine and methylphenidate, currently the drugs of choice in the treatment of attention deficit disorder, potently increase $\mathrm{ACh}$ release in the rat frontal cortex (Day and Fibiger, 1992; Acquas and Fibiger, 1996) and hippocampus (Day and Fibiger, 1994). This raises the possibility that these psychostimulants produce their beneficial effects on attention by virtue of their actions on cortical and/or hippocampal ACh release. The finding that $d$-amphetamine fails to ameliorate impaired performance in a five choice serial reaction time task produced by nucleus basalis lesions (Muir et al., 1995) is consistent with the hypothesis that basal forebrain cholinergic neurons are a substrate for the effects of $d$-amphetamine on attentional tasks.

According to Buzsaki and Gage (1991), the structural and functional requirements of a system that underlies cortical activation or arousal include the following: the system must (1) innervate the entire cerebral cortex, (2) target individual cortical columns in an anatomically selective manner, (3) release a neurotransmitter that enhances the effectiveness of other inputs, (4) show changes in activity that correlate with cortical activation and behavioral arousal, and (5) be activated similarly by different sensory afferents. Together with previous studies, the present findings indicate that the cholinergic basal nuclear complex meets these criteria. Furthermore, the present results demonstrate that sensory stimulation-induced increases in cortical and hippocampal $\Lambda \mathrm{Ch}$ release are not an inherent property of the stimulus. Rather, such increases depend on the context in which the stimulus is presented. This is what an attentional hypothesis of basal forebrain cholinergic function would predict. At present it is not possible to ascribe specific arousal-related functions (e.g., arousal vs vigilance vs selective attention) to the cholinergic basal nuclear complex with any degree of precision, and this will be an important priority for future research. Finally, it is worth mentioning that although attention has traditionally been discussed in the context of cortical function, there is growing evidence that the hippocampal formation is involved in some attentional processes (Han et al., 1995). The fact that a broad range of stimuli produce parallel increases in cortical and hippocampal ACh release emphasizes the potential importance of basal forebrain cholinergic neurons in regulating and coordinating different aspects of attention subserved by these two structures.

\section{REFERENCES}

Acquas E, Fibiger HC (1996) Chronic lithium attenuates dopamine D1receptor mediated increases in acetylcholine release in rat frontal cortex. Psychopharmacology, in press.

Apostol $G$, Creutzfeldt $O$ (1974) Cross correlation between the activity of septal units and hippocampal EEG during arousal. Brain Res 67:65-75.

Bartus RT, Flicker C, Dean RL, Pontecorvo M, Figueiredo JC, Fischer SK (1985) Selective memory loss following nucleus basalis lesion: long term behavioral recovery despite persistent cholinergic deficiencies. Pharmacol Biochem Behav 23:125-135.

Bartus RT, Pontecorvo M, Flicker C, Dean RL, Figueiredo JC (1986) Behavioral recovery following bilateral lesion of the nucleus basalis does not occur spontaneously. Pharmacol Biochem Behav 24:1287-1292.

Broks P, Preston GC, Traub M, Poppleton P, Ward C, Stahl SM (1988) Modelling dementia: effects of scopolanine on menury and attention. Neuropsychologia 26:685-700.

Buzsaki G, Gage FH (1991) Role of the basal forebrain cholinergic system in cortical activation and arousal. In: Activation to acquisition: functional aspects of the basal forebrain cholinergic system (Richardson RT, ed), pp 115-133. Boston: Birkhäuser.

Buzsaki G, Bickford RG, Ponomareff G, Thal LJ, Mandel R, Gage FH (1988) Nucleus basalis and thalamic control of ncocortical activity in the freely moving rat. J Neurosci 8:4007-4026.

Callahan MJ, Kinsora JJ, Harbaugh RE, Reeder TM, Davis RE (1993) Continuous ICV infusion of scopolamine impairs sustained attention of rhesus monkeys. Neurobiol $\Lambda$ ging 14:47 151.

Casamenti F, Deffenu G, Abbamondi AL, Pepeu G (1986) Changes in cortical acetylcholine output induced by modulation of the nucleus basalis. Brain Res Bull 16:689-695.

Damsma G, Westerink BHC, de Vries JB, Van der Berg CJ, Horn AS (1987) Measurement of acetylcholine release in freely moving rats by means of automated intracerebral dialysis. J Neurochem 48:1523-1528.

Davies P (1979) Neurotransmitter-related enzymes in senile dementia of the Alzheimer type. Brain Res 171:319-327.

Davies P, Maloney AJF (1976) Selective loss of central cholinergic neurons in Alzheimer's disease. Lancet 2:1403. 
Day J, Fibiger HC (1992) Dopaminergic regulation of cortical acetylcholine release. Synapse 12:281-286.

Day J, Fibiger HC (1994) Dopaminergic regulation of septohippocampal cholinergic neurons. J Neurochem 63:2086-2094.

Day J, Damsma G, Fibiger HC (1991) Cholinergic activity in the rat hippocampus, cortex and striatum correlates with locomotor activity: an in vivo microdialysis study. Pharmacol Biochem Behav 38:723-729.

Dudar JD (1975) The effect of septal nuclei stimulation on the release of acctylcholinc from the rabbit hippocampus. Brain Res 83:123-133.

Dudar JD, Whishaw IQ, Szerb JC (1979) Release of acetylcholine from the hippocampus of freely moving rats during sensory stimulation and running. Neuropharmacology 18:673-678.

Dunnett SB, Everitt BJ, Robbins TW (1991) The basal forebrain-cortical cholinergic system: interpreting the functional consequences of excitotoxic lesions. Trends Neurosci 14:494-501.

Eagger S, Levy R, Sahakian BJ (1991) Tacrine in Alzheimer's disease. Lancet 337:989-992.

Fibiger HC (1982) The organization and some projections of cholinergic neurons of the mammalian forebrain. Brain Res Rev 4:327-388.

Han J-S, Gallagher M, Holland P (1995) Hippocampal lesions disrupt decrements but not increments in conditioned stimulus processing. J Neurosci 15:7323-7329.

IIars B, Maho C, Edcline J-M, Hcnncvin E (1993) Basal forcbrain stimulation facilitates tone-evoked responses in the auditory cortex of the awake rat. Neuroscience 56:61-74.

Imperato A, Di Chiara G (1985) Dopamine release and metabolism in awake freely moving rats after systemic neuroleptics as studied by trans-striatal dialysis. J Neurosci 5:297-306.

Inglis FM, Fibiger HC (1995) Increases in hippocampal and frontal cortical acetylcholine release associated with presentation of sensory stimuli. Neuroscience 66:81-86.

Inglis FM, Day JC, Fibiger HC (1994) Enhanced acetylcholine release in hippocampus and frontal cortex during the anticipation and the consumption of a palatable meal. Neuroscience 62:1049-1056.

Jones DNC, Higgins GA (1995) Effect of scopolamine on visual attention in rats. Psychopharmacology 120:142-149.

Kim J, Fanselow M (1992) Modality-specific retrogradc amncsia of fcar. Science 256:675-677.

Krnjevic K, Ropert N (1982) Electrophysiological and pharmacological characteristics of facilitation of hippocampal population spikes by stimulation of the medial septum. Neuroscience 7:2165-2183.

Metherate R, Ashe JH (1992) Cellular bases of neocortical activation: modulation of neuron oscillations by the nucleus basalis and endogenous acetylcholine. J Neurosci 12:4701-4711.

Metherate R, Tremblay N, Dykes RW (1987) Acetylcholine permits long-term enhancement of neuronal responsiveness in cat primary somatosensory cortex. Neuroscience 22:75-81.

Metherate R, Ashe JH, Weinberger NM (1990) Acetylcholine modifies neuronal acoustic rate-level functions in guinea pig auditory cortex by an action at muscarinic receptors. Synapse 6:363-368.

Mizuno T, Endo Y, Arita J, Kimura F (1991) Acetylcholine release in the rat hippocampus as measured by the microdialysis method correlates with motor activity and exhibits a diurnal variation. Neuroscience 44:607-612.

Muir JL, Dunnett SB, Robbins TW, Everitt BJ (1992) Attentional functions of the basal forebrain cholinergic systems: effects of intraventricular hemicholinium, physostigmine, basal forebrain lesions and intracortical grafts on a multiple-choice serial reaction time task. Exp Brain Res 89:611-622.

Muir II, Page K.I, Sirinathsinghji D.JS, Robbins TW, Everitt BJ (1993) Excitotoxic lesions of basal forebrain cholinergic neurons: effects on learning, memory and attention. Behav Brain Res 57:123-131.

Muir JL, Everitt BJ, Robbins TW (1994) AMPA-induced excitotoxic lesions of the basal forebrain: a significant role of the cortical cholinergic system in attentional function. J Neurosci 14:2313-2326.

Muir JL, Everitt BJ, Robbins TW (1995) Reversal of visual attention dysfunction following lesion of the cholinergic basal forebrain by physostigmine and nicotine but not by the $5-\mathrm{HT}_{3}$ receptor antagonist, odansetron. Psychopharmacology 118:82-92.

Nilsson OG, Kalen P, Rosengren E, Bjorklund A (1990) Acetylcholine release in the rat hippocampus as studied by microdialysis is dependent on axonal impulse flow and increases during behavioral activation. Neuroscience 36:325-338.

Olton DS, Wenk GI. (1987) Dementia: animal models of the cognitive impairments produced by degeneration of the basal forebrain cholin- ergic system. In: Ysychopharmacology-the third generation of progress (Meltzler HY, ed), pp 941-953. New York: Raven.

Parasuraman R, Martin A (1994) Cognition in Alzheimer's disease: disorders of attention and semantic knowledge. Curr Opin Neurobiol 4:237-244

Paxinos G, Watson C. (1986) The rat brain in stereotaxic coordinates, 2 nd Ed. Sydney: Academic.

Perry EK, Perry RH, Blessed G, Tomlison BE (1977) Necropsy evidence of central cholinergic deficits in senile dementia. Lancet 1:89.

Perry EK, Blessed G, Tomlison BE, Perry RH, Crow TJ, Cross AJ, Dockray GJ, Dimaline R, Arregui G (1981) Neurochemical activities in human cemporal lobe related to aging and Alzheimer-type changes. Neurobiol Aging 2:251-256.

Phillips RG, Le Doux JE (1994) Lesions of the dorsal hippocampal formation interfere with background but not foreground contextual fear conditioning. Learn Memory 1:34-44.

Pirch JH, Rucker HK, Turco K (1991) Basal forebrain modulation of cortical cell activity during conditioning. In: The basal forebrainanatomy to function, Vol 245 (Napier TC, Kaliwas P, Hanin H, eds), pp 219-231. New York: Plenum

Pirch JH, Turco K, Rucker HK (1992) A role for acetylcholine in conditioning-related responses of rat frontal cortex neurons: microiontophoretic evidence. Brain Res 586:19-26.

Rasmusson DD, Clow K, Szerb JC (1992) Frequency-dependent increases in cortical acetylcholine release evoked by stimulation of the nucleus basalis magnocellularis in the rat. Brain Res 594:150-154.

Richardson RT, De Long MR (1988) A reappraisal of the nucleus basalis of Meynert. Trends Neurosci 11:264-267.

Richardson RT, De Long MR (1990) Context-dependent responses of primate nucleus basalis in a go/no-go task. J Neurosci 10:2528-2540.

Richardson RT, De Long MR (1991) Functional implications of tonic and phasic activity changes in nucleus basalis neurons. In: Activation to acquisition-functional aspects of the basal forebrain system (Richardson RT, ed), pp 135-166. Boston: Birkhäuser.

Rigdon GC, Pirch JH (1986) Nucleus basalis involvement in conditioned neuronal responses in the rat frontal cortex. J Neurosci 6:2535-2542.

Rolls ET, Sanghera MK, Roper-Hall A (1979) The latency of activation of neurons in the lateral hypothalamus and substantia innominata during feeding in the monkey. Brain Res 164:121-135.

Sahakian BJ, Jones G, Levy R, Gray J, Warburton D (1989) The effects of nicotine on attention, information processing, and short-term memory in patients with dementia of the Alzheimer type. Br J Psychiatry 154:797-800.

Sahakian BJ, Owen AM, Morant MJ, Eagger SA, Boddington S, Crayton L, Crockford HA, Crooks M, Hill K, Levy R (1993) Further analysis of the cognitive effects of tetrahydroaminoacridine (THA) in Alzheimer's disease: assessment of attentional and mnemonic function using CANTAB. Psychopharmacology 110:396-401.

Sarter M (1994) Neuronal mechanisms of the attentional dysfunction in senile dementia and schizophrenia: two sides of the same coin? Psychopharmacology 114:539-550.

Schwaber JS, Rogers WT, Satoh K, Fibiger HC (1987) Distribution and organization of cholinergic neurons in the rat forebrain by computeraided data acquisition and three-dimensional reconstruction. $J$ Comp Neurol 263:309-325.

Selden NRW, Everitt BJ, Jarrards LE, Robbins TW (1991) Complementary roles for the amygdala and hippocampus in aversive conditioning to explicit and contextual cues. Neuroscience 42:335-350.

Sillito AM, Kemp JA (1983) Cholinergic modulation of the functional organization of the cat visual cortex. Brain Res 289:143-155.

Sims NR, Bowen DM, Allen SJ, Smith CCT, Neary D, Thomas DJ, Davison AN (1983) Presynaptic cholinergic dysfunction in patients with dementia. J Neurochem 40:503-509.

Sweeney JE, Lamour Y, Bassant MH (1992) Arousal-dependent properties of medial septal neurons in the unanesthetized rat. Neuroscience 48:353-362.

Voytko ML, Olton DS, Richardson RT, Gorman LK, Tobin JR, Price DL (1994) Basal forebrain lesions in monkeys disrupt attention but not learning and memory. J Neurosci 14:167-186.

Whitehouse PJ, Price DL, Struble RG, Clark AW, Coyle J, De Long MR (1982) Alzheimer's disease and senile dementia: loss of neurons in the basal forebrain. Science 215:1237-1239.

Wilson FAW, Rolls ET (1990) Neuronal responses related to reinforcement in the primate basal forebrain. Brain Res 509:213-231. 